\title{
Education, Practice, and Research in Nursing Terminology: Gaps, Challenges, and Opportunities
}

\author{
H.-A. Park', I. Cho ${ }^{2}$ \\ 'College of Nursing, Seoul National University, Seoul, South Korea \\ ${ }^{2}$ Department of Nursing, Inha University, Incheon, South Korea
}

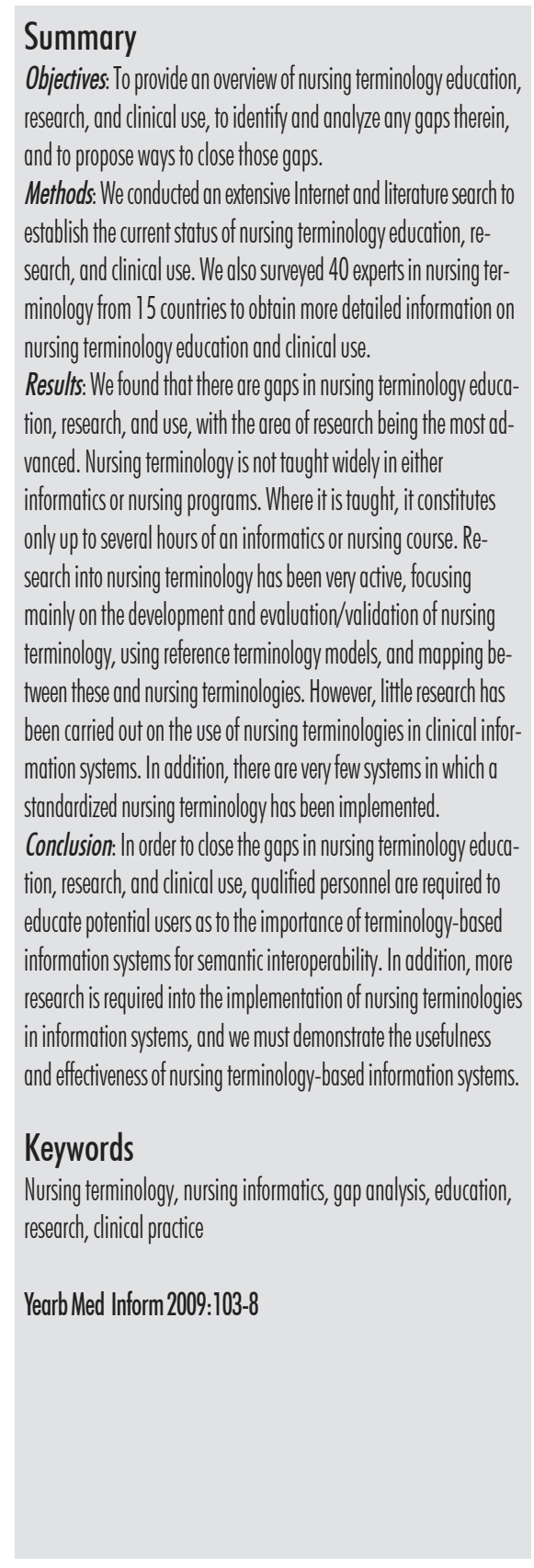

\section{Introduction}

Computer-based patient record systems are being introduced throughout the world to overcome many of the logical, organizational, and other practical limitations of traditional paper-based patient records, and to provide the additional benefits that accompany information and communication technology. Since a significant amount of patient data is becoming available in computerbased patient records, use of the data for purposes other than traditional archiving and reporting is becoming feasible. However, the capture, storage, and use of patient data in computer systems can be complicated if there is no agreement on vocabulary and meanings thereof.

With information-management tools, clinical reminders, and alerts, linkages with knowledge resources for healthcare decision support, and analysis of aggregate data are possible. To realize these possibilities, all patient problems and activities of health-care professionals should be recorded in a standardized and consistent manner. Thus, coded terminologies, vocabularies, and nomenclatures have been developed to ease the communication of coded health-care information [1]. Nursing is no exception in this regard.

Standardized terminologies are necessary to represent and document the client data, focus of care, and nursing activities properly. Significant efforts during the past 25 years have resulted in the development of standardized ter- minologies for the core phenomena of nursing practice: (1) patient problems (nursing diagnoses, signs, and symptoms); (2) interventions, including those focused on prevention and health promotion; (3) nursing outcomes [2].

There are many nursing terminologies available throughout the world. The American Nurses Association (ANA) has considered that the following 13 terminologies are appropriate for supporting clinical practice: Nursing Minimum Data Sets, and Nursing Management Minimum Data Sets as data element sets; North American Nursing Diagnosis Association (NANDA), Nursing Interventions Classification (NIC), Nursing Outcomes Classification (NOC), Omaha System, Clinical Care Classification (CCC), Patient Care Data Set, Perioperative Nursing Data Set, International Classifications for Nursing Practice (ICNP) as nursing-developed terminologies; Systematized Nomenclature of Medicine (SNOMED), Logical Observation Identifiers Names and Codes (LOINC), and Alternative Billing Codes $(\mathrm{ABC})$ as multidisciplinary terminologies [3].

There are many benefits of using standardized terminologies. They facilitate electronic data collection at the point of care, retrieval of relevant data, and data reuse for quality and cost monitoring and reporting. Standards for clinical information encoding can save system developers from reinventing the wheel. The use of commonly accepted standards can facilitate the exchange of data between systems [1]. 
These benefits can be maximized by the development and improvement of nursing terminology through research. If nursing terminologies were taught as a topic at the baccalaureate level, it might facilitate the use of nursing terminologies in clinical practice. Furthermore, nursing terminology should be available in clinical practice through terminology-based electronic nursing information systems. This in turn will produce data that can be reused for clinical practice and research.

However, there are gaps in nursing terminology in nursing informatics that prevent the realization of some of the benefits that we expect from the implementation of terminology-based nursing information systems. We would like to identify these gaps and the challenges and opportunities that can be used to bridge them. To this end, we present herein the current issues and developments in nursing terminology education, practice, and research, illustrating where the current gaps exist with regard to linking these three aspects of nursing terminology. We also suggest how these gaps can be filled.

\section{Methods}

We conducted an extensive Internet search and literature review to establish the current status of nursing terminology education, research, and clinical use. We reviewed nursing informatics programs posted on the American Medical Informatics Association (AMIA) Nursing Informatics Working Group (NI-WG) website (http:// www2 .amia.org/mbrcenter/wg/ni/ education.asp [4]). On this website, we found 30 institutions with nursing informatics curriculums. Through web links, we identified and reviewed the specific nursing informatics programs to establish whether nursing terminologies were being taught. We classified these institutions into three types of nursing informatics education based on whether they are a part of a nursing graduate program or not, and then whether they are a nursing informaticsfocused program or not: graduate program with a nursing informatics focus; individual courses on nursing informatics as part of a nursing graduate program; and continuing education/ professional development in nursing informatics. And then we further classified nursing terminology education into five types based on the integration of nursing terminology into programs: integrated into medical/bioinformatics vocabulary courses; no relevant courses; explicitly integrated into a nursing informatics curriculum; implicitly integrated into a nursing informatics curriculum; and episodic program. We differentiated the explicit integration from the implicit integration based on specific descriptions of nursing vocabulary or language standards in the nursing informatics curriculum. For example, only the School of Nursing University of WisconsinMadison-which forms part of the committee for institutional cooperation to share resources and coordinate collaborative activities in the USA-has language and standards in the description of the three-credit Health Information System course.

To obtain information on nursing terminology research, we searched literature databases such as PubMed, CINAHL, and ERIC, using the keywords "nursing," "terminology," "vocabulary," "classification," "thesaurus," "taxonomy," and "information system." We found 106 articles on nursing terminologies and health-care terminologies used in nursing, published in English, since 2000. We excluded studies of terminologies with no code and no relevance to information systems. As a result, we reviewed only 21 original research articles. We categorized these articles based on the framework we developed as part of this work (Figure 1). This framework has two layers with nursing terminology and nursing terminology models, and five phases of a terminology life cycle from development to clinical use.
In addition, we recruited 32 experts in nursing terminologies from 15 countries through the IMIA Nursing Informatics Special Interest Group. These experts were surveyed using two questions regarding the education of nursing informatics and the clinical use of nursing terminologies. We provided the background information of our research and then asked two questions. First, we asked if nursing terminologies are being taught as part of their BS, MS, NP, or $\mathrm{Ph} . \mathrm{D}$ programs at their institutes or in their countries, and if so, for how many hours and with what content (for example, data element sets, nursing-developed terminology, or multidisciplinary terminologies). Secondly, we asked if nursing terminologies are being used in the nursing information system employed at their institutes or in their countries and, if so, what kinds (locally developed terminologies, existing nursing terminologies, or multidisciplinary terminologies).

\section{Results}

\section{Nursing Terminology Education}

From the review of 37 websites of nursing informatics postgraduate education institutes we identified from the AMIA NI-WG website, we found 3 types of nursing informatics education (Table 1): as part of a nursing informatics graduate program, individual courses as part of a nursing graduate program, and continuing education/profession development programs. Regardless of the type of nursing informatics education, nursing terminology is not taught as an independent course in any of these institutes.

Nursing terminology is taught as part of a nursing informatics courses (e.g., Columbia University) or as part of a medical vocabulary course (e.g., Utah University). Nursing terminology is taught as part of a health information systems course in a consortium of 12 research universities in 8 Midwestern states of the USA. Nursing termi- 
nology is also taught at workshops and tutorials on standard terminologies at academic conferences such as those of the AMIA, Medinfo, HIMSS, MINING (MInnesota Nursing INformatics Group), TIGER (Technology Informatics Guiding Educational Reform), and NLN (National League for Nursing) Task Group on Informatics Competencies, and subsequent initiatives. This search yielded no data regarding how many hours of nursing terminology are being taught or the content of what is being taught in nursing terminology education.

From the e-mail survey of 30 experts from 15 countries, we were able to obtain more detailed information on nursing terminology education. It is rare for there to be a terminology-focused objective on any curriculum for a noninformatics degree at any level of nursing education. Nursing terminology is taught either as part of a nursing informatics or nursing course in a nursing program, or it is taught as part of a nursing informatics course in other programs. For example, Seoul National University School of Nursing in Korea teaches nursing terminology as part of a nursing informatics course. Finnish universities teach nursing terminology as part of a nursing course in nursing education. Moreover, one German university teaches nursing terminology as part of a nursing informatics course in a health informatics program.

Most of the undergraduate programs that were surveyed in the USA, Japan, Korea, Brazil, and Taiwan taught NANDA as part of care planning. For most informatics programs in advanced nursing programs, nursing terminology education is part of an elective course for nursing or health/medical informatics programs (MS and Ph.D) and is allocated a teaching time ranging from 2 hours to 20-30 hours. The main topics covered include an introduction to health and nursing terminologies and the purpose of each terminology. However, some advanced topics are taught on special occasions, including Basic principles of health terminology devel-

Table 1 An overview of nursing terminology education in nursing

\begin{tabular}{|l|l|c|}
\hline \multicolumn{1}{|c}{$\begin{array}{c}\text { Type of Nursing Informatics } \\
\text { Education }\end{array}$} & \multicolumn{1}{|c|}{ Type of Nursing Terminology Education } & $\begin{array}{c}\text { Number of } \\
\text { Institutes* }\end{array}$ \\
\hline \multirow{2}{*}{$\begin{array}{l}\text { Graduate program with nursing } \\
\text { informatics focus }\end{array}$} & Integrated into the medical/bioinformatics vocabulary curriculum & 2 \\
\cline { 2 - 3 } & Implicitly integrated into the nursing informatics curriculum & 14 \\
\cline { 2 - 3 } & Explicitly integrated into the nursing informatics curriculum & 3 \\
\hline $\begin{array}{l}\text { Individual courses on nursing } \\
\text { informatics as part of a nursing } \\
\text { graduate program }\end{array}$ & No relevant course & 6 \\
\hline $\begin{array}{l}\text { Continuing education/professional } \\
\text { development }\end{array}$ & Episodic program (workshops/conferences) & \\
\hline
\end{tabular}

*The number of institutions can exceed the total since some institutions offer more than one type of nursing informatics education

opment and use; A brief summary of the historical development, purpose, and evaluation of nursing terminologies; Introduction to SNOMED Clinical Terms and exercise in modeling; Discussion of the relationship between terminology, classifications, and data sets; Terminology standards (CEN, ISO); Approaches to evaluating terminologies and linked information artifacts based on principles of fitness for purpose, safety, implementability, and interoperability. For nurse-practitioner programs, coding for disease and procedures such as ICD (International Classification of Diseases) and CPT (Current Procedural Terminology) are taught for billing.

Fortunately, nursing terminology is increasingly being included in the nursing curriculum in some countries. For example, in the USA, inclusion of nursing terminology in the nursing curriculum is increasing in part because of pressure from two sources: accreditation and TIGER, an organization that was formed to increase the inclusion of automation and terminologies. Another example is Canada. A Canadian national initiative, the Canadian Health Outcome for Better Information and Care (C-HOBIC) project is having an impact on nursing terminology education in Ontario, Saskatchewan, Manitoba, and Prince Edward Island.
The Canadian Nurses Association is working with the nursing education programs in those provinces to develop curriculum material around the $\mathrm{C}$ HOBIC concepts and terminology. In Finland, nurse educators have agreed on which topics in decision making and nursing documentation are to be covered in nursing education. With this agreement, all universities have included the nursing process model into their curriculums at the BS and NP level. Currently half of the Canadian universities are participating in a national development project for nursing documentation, which focuses on the adoption of the translated CCC.

Based on the websites and experts we surveyed, nursing terminology is rarely taught in undergraduate programs, even though NANDA is being taught as part of nursing process education in some countries. At the graduate program level, nursing terminology is only taught as part of the nursing informatics graduate program. In addition, nursing terminology education is being carried out in the form of tutorials or workshops at informatics conferences. Topics covered in most of nursing terminology education are limited to the nursing terminologies themselves with rare occassions covering some advanced topics such as reference terminology and interoperability. 


\section{Nursing Terminology Research}

We categorized nursing terminologyrelated research into five groups according to the developmental phase of the terminology, from development to use in clinical systems, based on the framework we developed as part of this work (Figure 1): development of nursing terminology; validation of nursing terminology (including cross-mapping between nursing terminologies); development of a reference terminology model; validation of the reference terminology model (including mapping the nursing terminology to the reference terminology); use of nursing terminology.

We found only one study on the development of nursing terminology since 2000 in the review; the development of CCC, which is an upgraded version of the Home HealthCare Classification [5]. However, there have been various studies on the evaluation of existing nursing terminologies [6-9]. There are many articles about nursing terminology models and reference terminology model development, such as the GALEN, the CEN model, and the ISO nursing reference terminology model [10-12], and on mapping existing nursing terminologies to reference terminologies [13-17]. There have been several studies on standardizing locally used nursing terminologies such as Korean, Japanese, and Finnish terminologies [18-21]. There are also studies cross-mapping between nursing terminologies as part of the interface development of a nursing terminology [22]. However, with the exception of one Korean study, there are no articles on the application of nursing terminologies in clinical practice [23]. There are several ICNP-based electronic nursing record systems that are up and running in Korea. Publications on the use of data stored in terminology-based nursing record systems are now beginning to appear in Korea [24].

IMIA Yearbook of Medical Informatics 2009

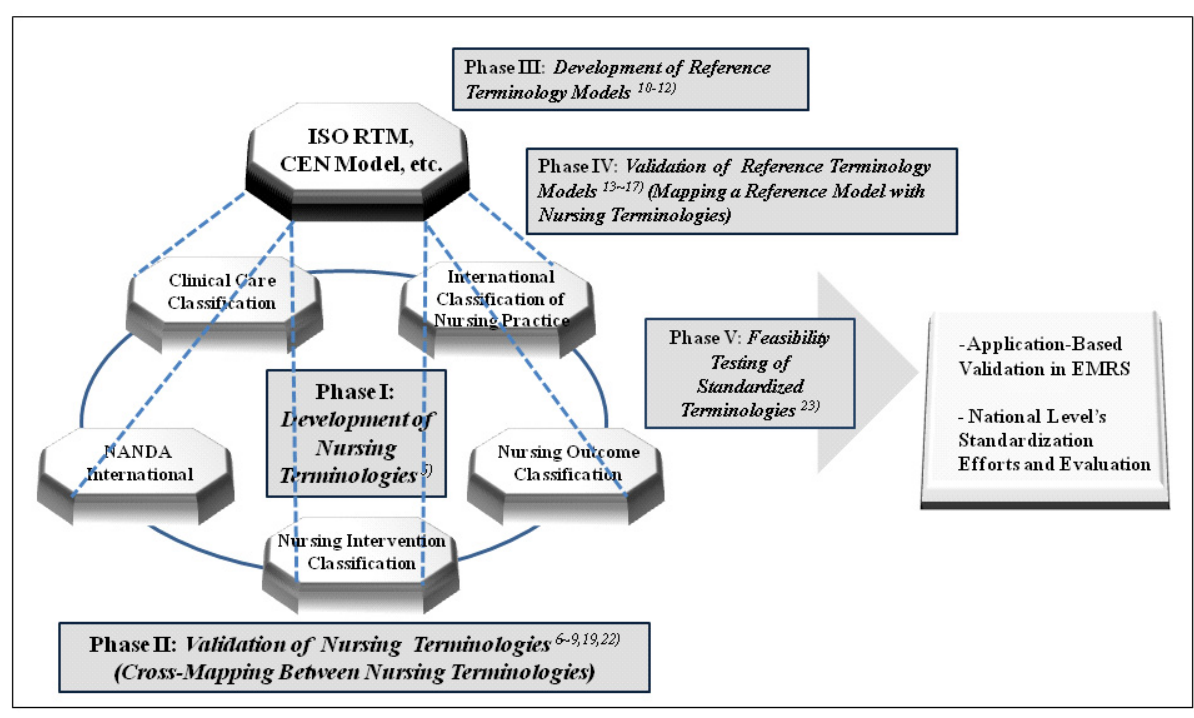

Fig. 1 Classification of nursing terminology research efforts and their inter-relationships

Note: ISO RTM stands for International Standard Organization Reference Terminology Model, CEN for European Committee for Standardization), and NANDA for North American Nurses Diagnosis Association

\section{Use of Nursing Terminology in Practice}

The results of the e-mail survey of 30 experts from 15 countries revealed that the countries we surveyed varied in terms of use of nursing terminology in health-care systems. At one extreme, there appear to be countries with no nursing information systems in their hospitals, let alone use of nursing terminologies, such as New Zealand. At the other extreme, there are countries in which a national nursing terminology is used in the nursing information systems; for example, the Swedes use a locally developed VIPS (VIPS is an acronym formed from the Swedish words for wellbeing, integrity, prevention, and security), which is used widely in the other Scandinavian countries.

There are no standardized nursing terminologies being used in most of the countries we surveyed. In these countries, hospitals have chosen to create their own information systems. Most hospitals with homegrown systems use homegrown terminologies for their systems. Hospitals with vendorcreated systems use vendor-created terminologies. Although most of the ven- dors claim that they have implemented standardized nursing terminologies in their systems, standardized terminologies are not always used.

However, with the increasing emphasis on the importance of semantic interoperability, hospitals and vendors are starting to look at nursing terminologies or are beginning to implement standardized nursing terminologies within their systems. For example, some hospitals and multinational vendors in the USA, such as Cerner and Siemens, use SNOMED CT and the ANA-recognized nursing terminologies in their systems. Some Korean hospitals use SNOMED CT and the ICNP.

Vendors usually provide existing controlled terminology such as SNOMED CT, LOINC, and their own created terminologies; however, they are very flexible in terms of the terminologies their clients use in their systems. Vendors usually only provide a structure that is contained within their terminology model so that their clients can use other terminologies not tied to the vendor-created terminology.

The number of commercially available software programs based on specific nursing terminologies is increas- 
ing dramatically. For example, Omaha System-enabled software is being used in the USA, UK, and New Zealand, CCC-enabled software is being used in the USA and Finland. NNN (NANDANIC-NOC)-enabled software is available in the USA and Korea.

Even though terminology-based systems are being introduced, these systems use more than one terminologies mapped together. One example would be a nursing information system supporting a nursing process mapped with NNN. In this case, we need to integrate various nursing terminologies and improve semantic interoperability between systems with nursing reference terminology models such as the ISO model and a reference terminology such as ICNP and SNOMED CT.

There are national initiatives to include standardized nursing terminology in health-care systems. The C-HOBIC project in Canada will implement the collection of patient outcome information-related nursing care in the electronic health records (EHRs) of four provinces. The structured language used in C-HOBIC will be mapped to the standardized clinical reference terminology of nursing, the ICNP. In Finland, the government has declared an Act on the national-health records system, which requires that a nursing minimum data set be implemented in every system, and that nursing diagnoses, interventions, and outcomes be documented with the CCC by 2011.

\section{Discussion}

From this study, we found two particular gaps that must be filled: education, and use of terminology in clinical practice. Standardized nursing terminologies have been developed and studied, but teaching about nursing terminology, the use of terminology in nursing education programs, and the incorporation of such standardized terminologies into electronic nursing records have lagged behind. This is due to the lack of real- ization of the importance of standard terminology in data exchange and sharing, and the lack of qualified faculty members with the skill set to teach nursing terminology to nursing students. Problems have occurred in the use of nursing terminology in electronic nursing records systems because users were unable to find the appropriate nursing terminology to meet their requirements, and even if there was one available, they did not know how to implement the terminology into their EHR system due to a lack of guidance.

To close the gaps, we need to produce qualified faculty members who will teach nursing terminology to students, who will then become future users of nursing terminology, and future researchers who will develop, evaluate, and implement nursing terminology. With limited resources, one solution would be to share resources and promote and coordinate collaborative activities across academic institutes and different countries, like the Committee for Institutional Cooperation in the USA (http://www.cic.net [25]). Through this kind of cooperation, informatics faculties can be shared and research activities can be collaborated. To ensure that terminology is taught in nursing informatics education, we need to promote the importance of a standardized nursing terminology for semantic interoperability.

To promote the use of nursing terminology in EHR systems, terminologies need to be detailed and comprehensive enough, and used within the information model standards allowing the linkage between terminology and information model. We also need to develop an interface for nursing terminology and user guides to promote the use of nursing terminology in EHR systems. Finally, users need to understand the terminology if it is to be fully incorporated into the system, even though most of the EHR systems are developed by the vendors.

In order to promote and disseminate nursing terminology education, research, and use, government, industry, academia, and health-care facilities must work together, each with a distinctive role to play. The government should establish and implement policy regarding the use of standardized terminology, and can introduce incentives to encourage the use of standardized terminology by the health-care organizations. The government can also play an important role in the establishment of a national governance structure to ensure semantic interoperability between terminologies.

Companies involved in the development of electronic medical record (EMR) and EHR systems need to apply standardized nursing terminology and manage nursing terminologies with a vocabulary server. Academia can participate in research to develop, evaluate, and test nursing terminologies. It can also conduct research to determine the advantages of nursing terminology use in EMR and EHR systems. Academia can also help by educating the future users and researchers of nursing terminology.

Health-care facilities and health-care providers are the ultimate users of nursing terminology in the information system, and as such continuously need to use, evaluate, and provide feedback to both industry and academia regarding their systems.

\section{Acknowledgements}

We would like to thank those experts who participated in the e-mail survey.

\section{References}

1. Shortliffe EH, Perreault,LE, Wiederhold G, Fagan LM. Medical Informatics: Computer Applications in Health Care and Biomedicine. New York: Springer; 1999.

2. Bakken S, Cimino JJ, Hripcsak G. Promoting patient safety through enabling evidence-based practice through informatics. Medical Care 2004;42:II49.

3. American Nursing Association. Nursing Informatics: Scope and Standards of Practice. Silver Spring: American Nurses Publishing; 2008.

4. Nursing Informatics Working Groups. Education in Nursing Informatics. AMIA NI-WG. Available from: http://www2.amia.org/mbrcenter/wg/ni/ education.asp.

5. Saba VK, Taylor SL. Moving past theory: use of a 
standardized, coded nursing terminology to enhance nursing visibility. Computers, Informatics, Nursing: CIN 2007; 25:324.

6. Cho I, Park HA. Development and evaluation of a terminology-based electronic nursing record system. J of Biomed Inform 2003;36:304

7. Bakken, S, Holzemer, WL, Portillo, CJ, Grimes R, Welch J, Wantland D. Utility of a standardized nursing terminology to evaluate dosage and tailoring of an HIV/AIDS adherence intervention. Journal of Nursing Scholarship: an Official Publication of Sigma Theta Tau International Honor Society of Nursing/Sigma Theta Tau 2005;37:251.

8. Junttila K, Salanterä S, Hupli M. Developing terminology for documenting perioperative nursing interventions. Int J Med Inform 2005;74:461.

9. Kennedy MA, Hannah K. Representing nursing practice: evaluating the effectiveness of a nursing classification system. Can J Nurs Res 2007;39:58.

10. Hardiker NR, Bakken S, Casey A, Hoy D. Formal nursing terminology systems: a means to an end. J Biomed Inform 2002;35:298.

11. Hardiker NR. Determining sources for formal nursing terminology systems. J Biomed Inform 2003; $36: 279$.

12. Matney S, Dent C, Rocha RA. Development of a compositional terminology model for nursing orders. Int J Med Inform 2004;73:625.

13. Bakken S, Warren JJ, Lundberg C, Casey A, Correia $\mathrm{C}$, Konicek D, et al. An evaluation of the usefulness of two terminology models for integrating nursing diagnosis concepts into SNOMED Clinical Terms. Int J Med Inform 2002;68:71

14. Moss J, Coenen A, Mills ME. Evaluation of the draft international standard for a reference terminology model for nursing actions. J Biomed Inform 2003;36:271

15. Ehnfors M, Angermo LM, Berring L, Ehrenberg A, Lindhardt T, Rotegard AK, et al. Mapping VIPS concepts for nursing interventions to the ISO reference terminology model for nursing actions: A collaborative Scandinavian analysis. Stud Health Technol Inform 2006;122:401.

16. Hwang J, Cimino JJ, Bakken S. Integrating nursing diagnostic concepts into the medical entities dictionary using the ISO Reference Terminology Model for Nursing Diagnostics. J Am Med Inform Assoc 2003;10:382.

17. Goossen W. Cross-mapping between three terminologies with the international standard nursing reference terminology model. Int J Nurs Terminol Classif 2006;17:153.

18. Park HA, Kim JH, Lee JH, Lee HY, Kim JW, KimWO, et al. Standardization of Korean nursing terminology. Stud Health Technol Inform 2006; 122:992.

19. Sagara K, Abe A, Ozaku HI, Kuwahara N, Kogure $\mathrm{K}$. Features of standardized nursing terminology sets in Japan. Stud Health Technol Inform 2006; $122: 471$.

20. Jokinen T, Ensio A, Saranto K. Using standardized terminology for nursing documentation. Stud Health Technol Inform 2006;122:995.

21. Ensio A, Saranto K, Ikonen H, Iivari A. The national evaluation of standardized terminology. Stud Health Technol Inform 2006;122:749.

22. Hyun S, Park HA. Cross-mapping the ICNP with NANDA, HHCC, Omaha system and NIC for unified nursing language system development. Int Nurs Rev 2002:49:99

23. Cho I, Park H. Evaluation of the expressiveness of an ICNP-based nursing data dictionary in a computerized nursing record system. J Am Med Inform Assoc 2006; 13:456.

24. Park H, Cho I, Jung E. Exploring use of a clinical data repository containing ICNP-based nursing practice data. Comput Inform Nurs. In press 2009.

25. CIC Home page. Committee on Institutional Cooperation. Available at: http://www.cic.net/.Accessed September 28, 2008.

\section{Correspondence to:}

Hyeoun-Ae Park

Associate Dean

Professor, Biostatistics and Health Informatics

College of Nursing Seoul National University

28 Yongon-dong Chongno-gu

Seoul, 110-799, Korea

Tel: +8227408803

Fax: +8227654103

E-mail: hapark@snu.ac.kr 